\title{
Characteristics of Vibration and Sound Radiation of Metro Resilient Wheel
}

\author{
Xin Zhou ${ }^{1,2}{ }^{0}$, Jian Han ${ }^{1}$, Yue Zhao ${ }^{3}$, Bing Wư 4 , Gong Cheng ${ }^{1}$, Shenghui Xu ${ }^{1}$ and Xuesong Jin ${ }^{1 *}$
}

\begin{abstract}
Resilient wheels are extensively used in urban rail transit, especially for tramway systems, owing to its advantages in noise reduction. A new type of resilient wheel for a metro is designed, and its characteristics of vibration and sound radiation, including the rolling noise of a resilient single wheel coupled with a track, are studied in this paper. A two-step research is presented. Firstly, laboratory experiments were conducted to obtain the vibration response of the designed resilient wheel under the radial excitation on its tread. Secondly, the rolling noise model of the resilient wheel coupled with a slab track used in a metro line is developed. The wheel model is based on the 3D finite element and boundary element methods and verified by using the experimental results obtained from the laboratory. The track vibration model is based on the wavenumber finite element method, and the track sound radiation is calculated by using an efficient frequency-domain Rayleigh method. The interaction of the resilient wheel and the slab track is analyzed considering the measured wheel/rail roughness of the metro. The contribution of the resilient wheel to the reduction of wheel/rail system noise is analyzed. The results show that the resilient wheel can effectively reduce the wheel/rail rolling noise by approximately $2 \mathrm{~dB}(\mathrm{~A})$ to $3 \mathrm{~dB}(\mathrm{~A})$, mainly because the radiated noise by the rail is reduced. In addition, the elastic modulus of the rubber has an important influence on the noise reduction of resilient wheels.
\end{abstract}

Keywords: Resilient wheel, Wheel/rail rolling noise, Noise reduction, Laboratory experiment, Finite element and boundary element methods

\section{Introduction}

The speed of metro trains is generally within $30 \mathrm{~km} / \mathrm{h}$ to $120 \mathrm{~km} / \mathrm{h}$. In this speed range, wheel/rail rolling noise is the primary noise source [1]. Metro lines use slab track structures; moreover, vibration isolation track structures with low vertical stiffness are used in special sections. The noise of both the slab tracks and vibration isolation tracks is higher than that of ballasted tracks primarily because of the increase in rail noise owing to the use of lower fastener stiffness to isolate the wheel and rail vibrations $[2,3]$.

At present, the measures for controlling wheel/rail noise in metro lines mainly include reducing the surface roughness of the wheel and rail and adopting low-noise wheels and rails [4]. When compared to the low-noise

\footnotetext{
*Correspondence: xsjin@swjtu.cn

${ }^{1}$ State Key Laboratory of Traction Power, Southwest Jiaotong University, Chengdu 610031, China

Full list of author information is available at the end of the article
}

rail, the use of low-noise wheel is a relatively simple process. It requires only partial changes to the wheel, which is inexpensive and easy to maintain. Ring damped wheels are mainly used to reduce the curve noise [5] and also to demonstrate a noise reduction effect on the rolling noise at frequencies above $2000 \mathrm{~Hz}$ [6]. Wheels that are damped with constrained layers of viscoelastic materials applied to the surface of the web can reduce the noise of the wheel at frequencies above $2000 \mathrm{~Hz}$ by approximately $5 \mathrm{~dB}$ [7]. Mounting a tuned mass damper on the wheel reduces the wheel/rail noise at frequencies above $2000 \mathrm{~Hz}[8,9]$. These measures mainly reduce the wheel noise; however, the noise reduction of the wheel/rail rolling noise is not obvious if the rail noise mainly contributes to the wheel/rail noise. When the surface of the wheel and rail is relatively smooth, the main frequency band of the interior noise is between $500 \mathrm{~Hz}$ to $1250 \mathrm{~Hz}$ [10]. When short wavelength corrugation exists in the wheel/rail surface, the interior noise appears as a significant peak at the excitation frequency corresponding to 
the corrugation. In the frequency band from $500 \mathrm{~Hz}$ to $1250 \mathrm{~Hz}$, the rail noise is always higher than the wheel noise by more than $10 \mathrm{~dB}$ [11]. Therefore, the above mentioned low-noise wheels, which demonstrate little effect on the rail noise, cannot effectively reduce the wheel/rail noise under the operating conditions of the metro.

A resilient wheel with a group of rubber bricks located between the rim and the web can affect the vibration and sound radiation of the wheel/rail system and reduce the wheel and rail noises. Resilient wheels have been widely used in urban rail transit, especially in trams [12, 13]. Koo et al. [14] measured the vibration and noise reduction by using resilient wheels in the metro. The resilient wheel in the straight section can reduce the interior noise by $4 \mathrm{~dB}(\mathrm{~A})$ to $5 \mathrm{~dB}(\mathrm{~A})$. Based on the TWINS theory $[15,16]$, some scholars adopted simulation methods to study the vibration and noise reduction characteristics of resilient wheels $[7,17-19]$ and determined that the elastic modulus of rubber has an important effect on sound radiation of resilient wheels [7, 17]. Cigada et al. [20] analyzed the coupling relationship between the resonance modes and the sound radiation of resilient wheel through experimental methods. Claus et al. [21, 22] established the vertical dynamics model of the ICE railway car to study the possibility of resilient wheels reducing the low frequency interior noise. Yang et al. [23] studied the longitudinal vibration law of a resilient wheel under low- and highspeed driving conditions. In previous research, there were hardly any studies on the reduction of vibration and noise for the application of resilient wheels under the operating conditions of the metro.

In this study, based on the mechanism of vibration and noise reduction of a resilient wheel, this paper analyzes the characteristics of vibration and noise reduction of resilient wheels. To analyze the noise, the wheel/rail rolling noise under the operating conditions of the metro line were considered.

\section{Laboratory Experiment on Resilient Wheel}

\subsection{Introduction of the Experiment}

Based on the application environment and the requirements of vibration and noise reduction of the metro wheel, a new type of metro resilient wheel structure was designed, as shown in Figure 1. The main components include the rim, web, rubber blocks, and mounting ring. The rubber blocks are interference fitted between the rim and the web. The rim, web, and rubber blocks are assembled by interference fit of the mounting ring and web. To further ensure safety, the bolt fastening is increased; moreover, the bolt is threaded through the mounting ring and rubber blocks and screwed to the inner side of the web.

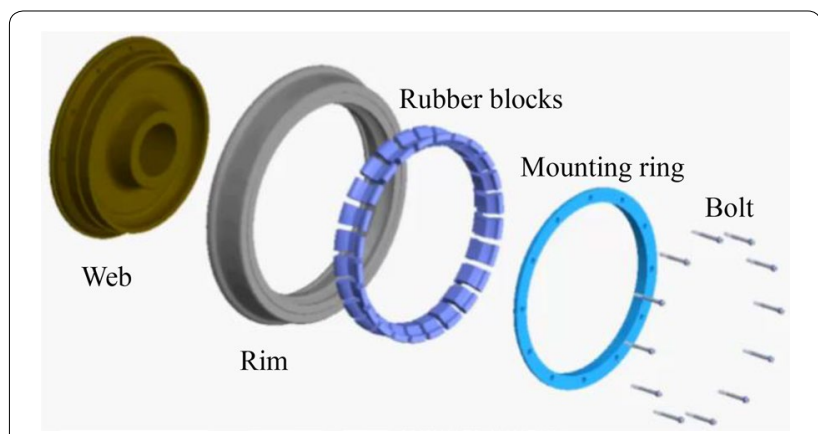

Figure 1 Structure of the new resilient wheel

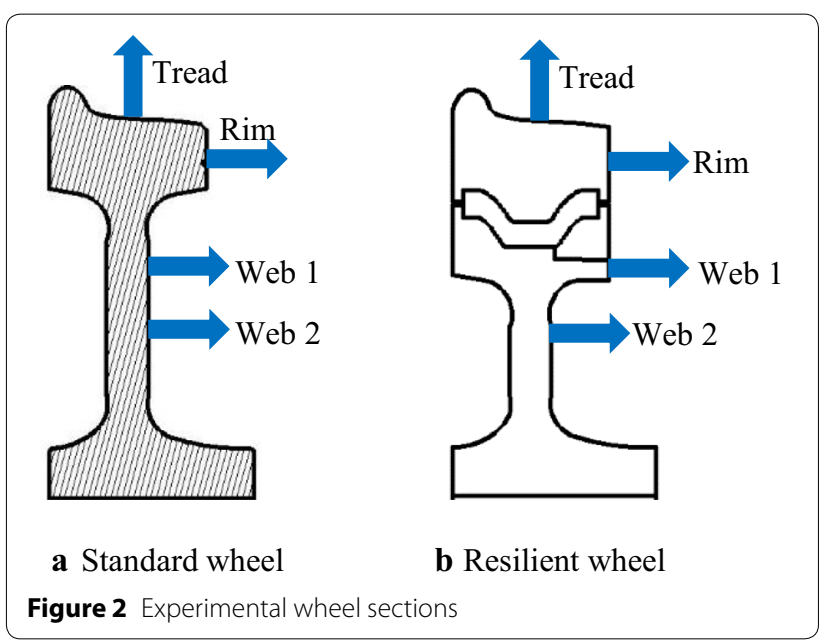

The resilient wheel is designed based on a B-type metro standard (or naked) wheel. The wheel sections are shown in Figure 2. Both the wheels consist of a straight web with $840 \mathrm{~mm}$ diameter, but with different values of mass. A standard wheel mass is $328 \mathrm{~kg}$, while the mass of a resilient wheel is $393 \mathrm{~kg}$, in which the rim mass is $202 \mathrm{~kg}$, the combined mass of the web and mounting ring is $185 \mathrm{~kg}$, and the rubber block mass is $6 \mathrm{~kg}$.

Because the static axle weight and running speed of the metro are higher than that of a tram (the general axle weight of the B-type metro is $14 \mathrm{t}$, the running speed is approximately $30 \mathrm{~km} / \mathrm{h}$ to $120 \mathrm{~km} / \mathrm{h}$; the general axle weight of tram is $11 \mathrm{t}$, and the running speed is approximately $20 \mathrm{~km} / \mathrm{h}$ to $60 \mathrm{~km} / \mathrm{h}$ ). Therefore, large values of radial and axial stiffness are required to be designed in metro resilient wheels to avoid excessive deformation of the rubber blocks and creep failure. In the section of a resilient wheel, the bottom of the rubber is mainly subjected to compression deformation, and its arcs on both sides are subjected to shearing and compression deformation. When compared to the existing V-shaped rubber resilient wheels, the newly designed resilient wheel has 
a larger contact area between the rubber and the metal, and also demonstrates greater radial stiffness for the same properties of the rubber.

To understand the characteristics of vibration and noise reduction while using a resilient wheel, the vibration characteristics of the standard wheel and the resilient wheel were measured. During the experiment, the two tested wheels were suspended on the cantilever support by using nylon ropes, as shown in Figure 3. To measure the vibration response of the wheel tread, rim, and web, the measuring points of the wheel vibrations are as shown in Figure 2. The positions for hitting the hammer are located on the tread.

\subsection{Vibration Characteristic}

The resilient wheel uses a group of rubber bricks between the rim and the web. An important parameter for determining the vibration absorption performance of the rubber is the damping ratio. The modal damping ratios of the standard and resilient wheels were obtained by using a half-power bandwidth method based on the measured frequency response function results. The modal damping ratio can be obtained by Eq. (1) [24]:

$$
\zeta=\left(f_{1}-f_{2}\right) /\left(2 f_{0}\right)
$$

In the formula, $\zeta$ is the modal damping ratio, $f_{1}$ is the upper limit frequency of the half-power bandwidth, $f_{2}$ is the lower limit frequency of the half-power bandwidth, and $f_{0}$ is the resonance frequency.

Figure 4 shows the modal damping ratios of the standard wheel and the resilient wheel at the main resonance frequencies.

As observed from Figure 4, the modal damping ratio of the standard wheel is approximately $0.1 \%$ within

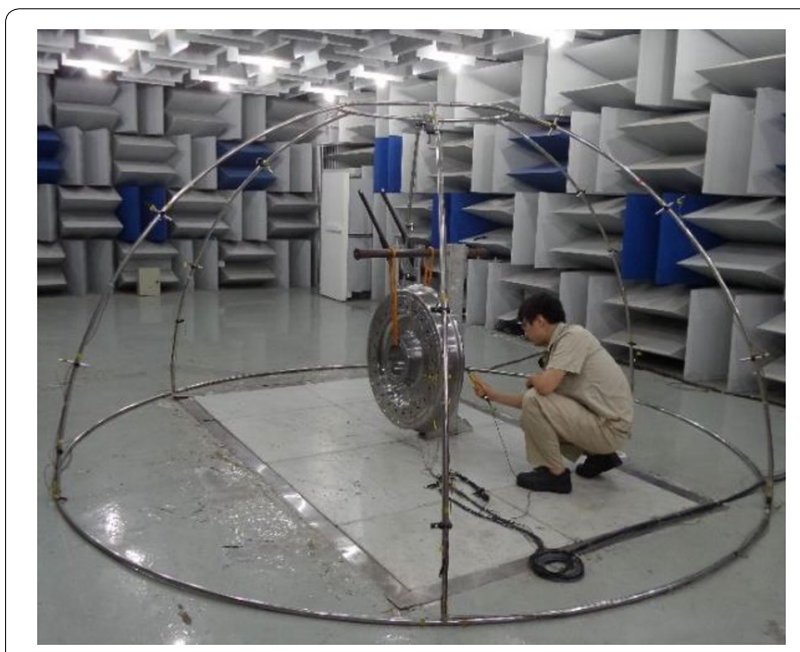

Figure 3 Wheel vibration experiment site

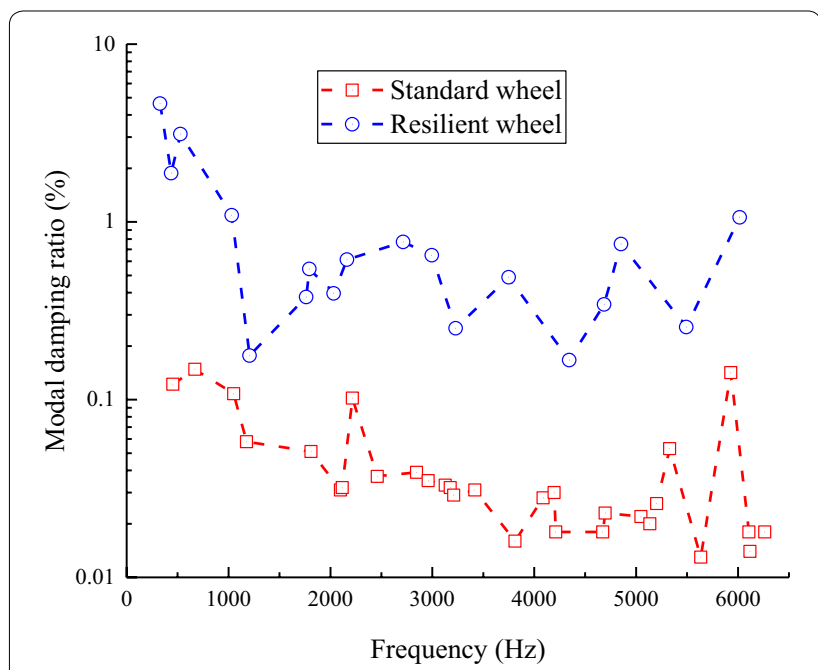

Figure 4 Experimentally identified modal damping ratio

$1000 \mathrm{~Hz}$, and it primarily distributes from $0.02 \%$ to $0.06 \%$ for frequencies above $1000 \mathrm{~Hz}$. For the resilient wheel, the modal damping ratio ranges primarily from $2 \%$ to $3 \%$ within $1000 \mathrm{~Hz}$, and it is approximately $0.5 \%$ for frequencies above $1000 \mathrm{~Hz}$. The modal damping ratio of the resilient wheel is approximately 10 times greater than that of the standard wheel; therefore, the resilient wheel performs better in vibration absorption. The damping ratio results obtained by measurements are similar to that in Ref. [20].

Figure 5 compares the measured radial mobility on the treads of the standard and resilient wheels to the radial excitations on the treads in the frequency domain. It is easy to excite the radial modes of the two wheels by using a hammer because of their straight web. The natural frequency corresponding to the radial mode of the resilient wheel is lower than that of the standard wheel, such as the modes (r, 2), (r, 3), (r, 4). This is due to the presence of rubber in the resilient wheel, which reduces the radial stiffness of the wheel rim. The excited first radial mode is the mode $(r, 2)$. The corresponding natural frequencies of the resilient and standard wheels are $523 \mathrm{~Hz}$ and $1813 \mathrm{~Hz}$, respectively. From $523 \mathrm{~Hz}$ to $1813 \mathrm{~Hz}$, the radial modes of the resilient wheel are relatively dense; further, its mobility is higher than that of the standard wheel. This can easily lead to an increase in the vibration of the rim. However, the influence on the wheel/rail rolling noise needs to be analyzed together with the vibration characteristics of the rail. Above the frequency of $1813 \mathrm{~Hz}$, the peak level of the resilient wheel mobility is one to two orders of magnitude lower than that of the standard wheel. This is mainly due to the damping energy dissipation of the 


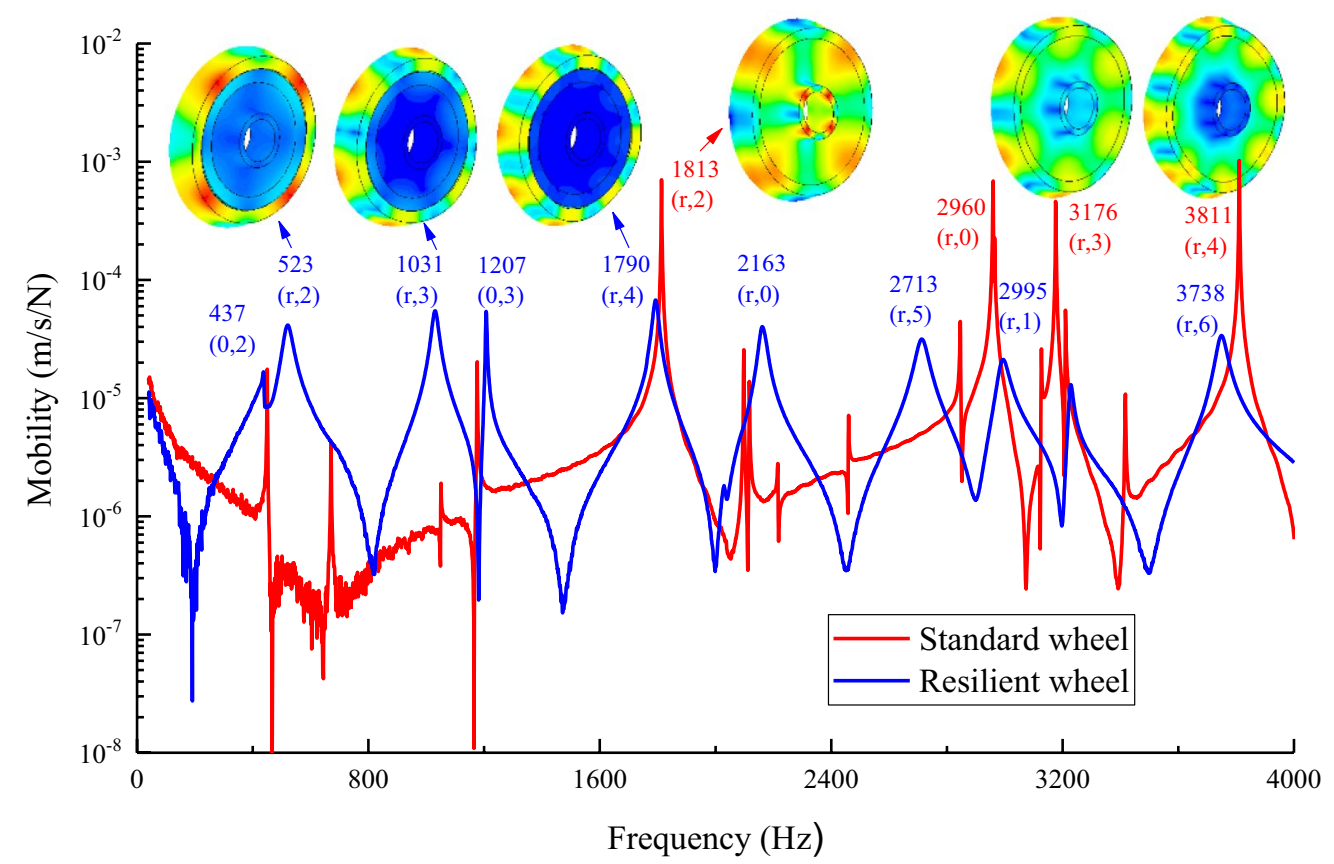

Figure 5 Tread radial response to a radial excitation on the tread

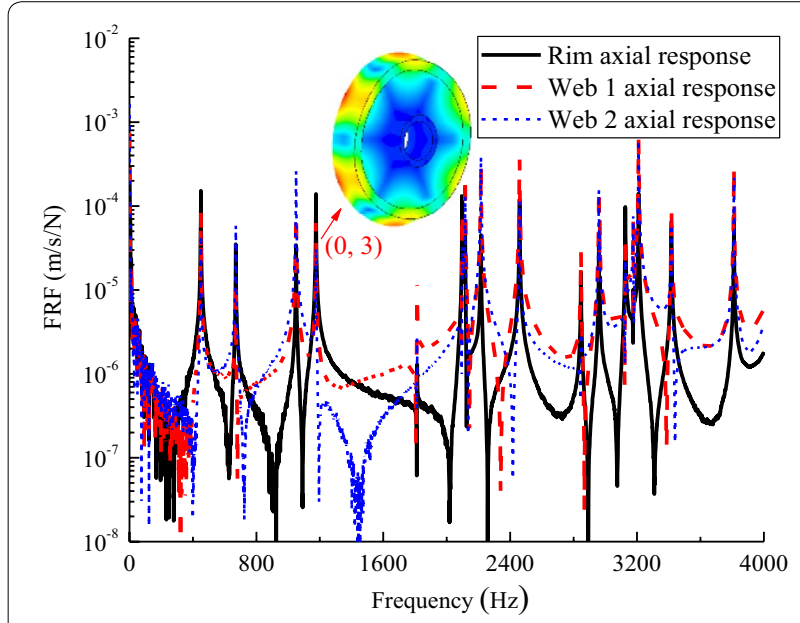

Figure 6 Axial response to radial excitation on the tread of the standard wheel

rubber layer, which reduces the vibration level of the tread of the resilient wheel.

The values of the axial frequency response function (FRF) of the rim, web 1, and web 2 under the radial excitation on the treads were also obtained experimentally, as shown in Figures 6 and 7. From Figure 6, it can be seen that the values of axial FRF of the rim, web 1, and web 2 of the standard wheel are not significantly different. From $1200 \mathrm{~Hz}$ to $1600 \mathrm{~Hz}$, the response of the standard wheel

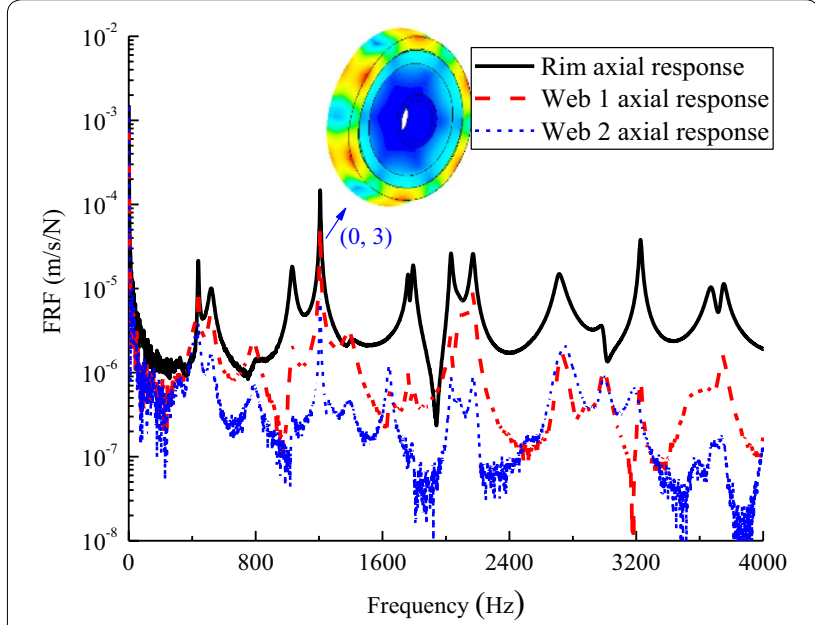

Figure 7 Axial response to radial excitation on the tread of the resilient wheel

is smaller because the number of resonance modes in this frequency range is rarer and cannot be easily excited using the hammer strike. This phenomenon is very similar to that discussed in Ref. [20].

It can be observed from Figure 7 that the axial velocity responses of the rim, web 1 , and web 2 significantly attenuate along the radial direction owing to the vibration isolation characteristics of the rubber. From the rim to 
web 2 , the vibration can attenuate by approximately one to two orders of magnitude. In most frequency bands, the velocity response of web 2 of the resilient wheel is smaller than that of the web 1 ; however, in the range of $2400 \mathrm{~Hz}$ to $3400 \mathrm{~Hz}$, the velocity response of web 2 is not significantly different from that of web 1 . This is because the vibration of the rim predominantly leads to the vibration of web 1 in most frequency bands. In the range of $2400 \mathrm{~Hz}$ to $3400 \mathrm{~Hz}$, owing to the presence of a pitch circle mode between web 1 and web 2 , the vibration amplitude of web 2 is close to that of web 1 .

Near $1200 \mathrm{~Hz}$, corresponding to the mode $(0,3)$ of the wheels, the vibration level of the resilient wheel is similar to that of the standard wheel. The resilient wheel does not demonstrate significant vibration reduction, which means that the vibrations of the rim and web are not decoupled in this mode.

\section{Wheel/Rail Rolling Noise Prediction Model}

Accurately obtaining the wheel surface vibration is critical to the accuracy of wheel/rail rolling noise prediction model. In this section, a wheel/rail rolling noise prediction model based on the resilient wheel is presented. The vibration and sound radiation is calculated using the finite element and boundary element methods. The vibration of the rail is obtained based on the Timoshenko beam model and the sound radiation of the rail is calculated by using an efficient frequency-domain Rayleigh method [25]. The calculation of the wheel/rail force in the model considers the measured wheel/rail roughness and the influence of wheel/rail contact filtering [26].

\subsection{Wheel Vibration and Sound Radiation Calculation}

A modal superposition method is widely used for the calculation of wheel vibrations [27]. The general form for solving the frequency response function of displacement using the modal superposition method is shown in Eq. (2):

$$
\alpha_{j k}(\omega)=\sum_{r=1}^{N} \frac{\varphi_{j r} \varphi_{k r}}{M_{r} \omega_{r}^{2}\left(1-\varpi_{r}^{2}+2 i \zeta_{r} \varpi_{r}\right)},
$$

where $\alpha_{j k}$ denotes the displacement response at the $x_{j}$ point, caused by a unit force that acts on the $x_{k}$ point of the wheel. $N$ is the number of wheel modes whose value is related to the analysis frequency.

$\varphi_{j r}$ and $\varphi_{k r}$ are the $j$ th and $k$ th components of the $r$ th mode shape, respectively. $M_{r}$ is the modal mass corresponding to the $r$ th mode shape. $\Omega_{r}$ is the natural frequency corresponding to the $r$ th mode shape. $\varphi_{j r}, \varphi_{k r}, M_{r}$, and $\omega_{r}$ are obtained from the finite element modal analysis of a 3D resilient wheel. Figure 8(a) shows the finite element (FE) mesh section. The elastic modulus and Poisson's ratio of rubber in the wheel FE model is $5 \times 10^{7} \mathrm{~Pa}$

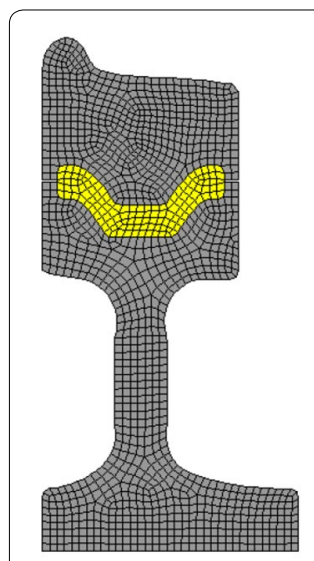

a

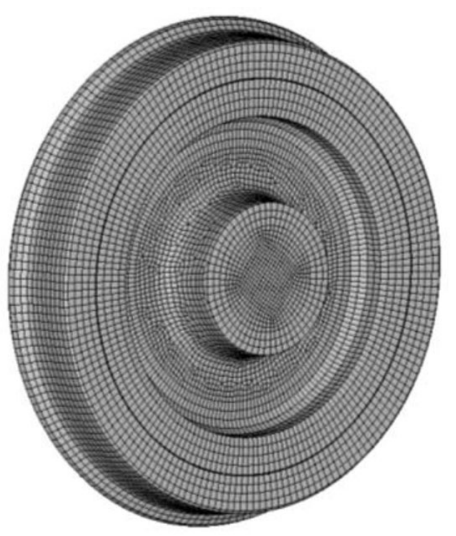

b
Figure 8 Models of resilient wheel: a Finite element mesh section; b Boundary element mesh

and 0.45 , respectively. The model using these parameters can ensure that the numerical natural frequencies of the model are closer to the experimental values. $\varpi=\omega / \omega_{r}$ is the frequency ratio. $\zeta_{r}$ is the modal damping ratio and is related to the modal frequency obtained from the results of the hammer experiment.

To validate the modal superposition method for the prediction of resilient wheel vibration, the results of the modal superposition method are compared with the experimental results in Section 2.2. Figure 9 shows the comparison results of the wheel velocity response under radial excitation on the tread.

For the tread radial and rim axial responses, the simulation and experimental results agreed well in frequency and amplitude. For two points of the web, the simulation results did not agree well with the experimental results; however, the simulation results could still reflect the vibration characteristics of the main frequencies. In general, the modal superposition method can effectively predict the vibration characteristics of resilient wheels and can be used for sound radiation calculations.

Using the modal superposition method, the wheel surface vibration under a unit force was obtained, and the sound power level of the wheel radiation could be calculated by the boundary element method (BEM). Figure $8(\mathrm{~b})$ shows the BEM model of the resilient wheel. In addition, the sound power level of the wheel excited by a unit force is tested in a semi-anechoic chamber. In the experiment, microphones were arranged at 20 points on the hemispherical envelope surface according to ISO 3745-2012 standard [28]. Figure 10 shows the comparison of the simulation and experimental results. It can be observed that the simulation and experimental results are well matched at the main peak frequencies, which 


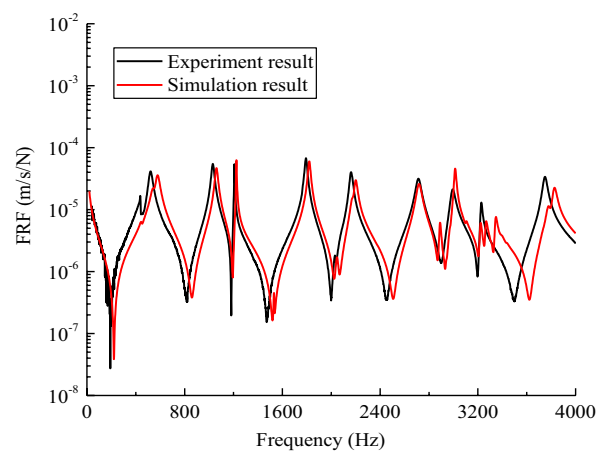

a Tread radial response

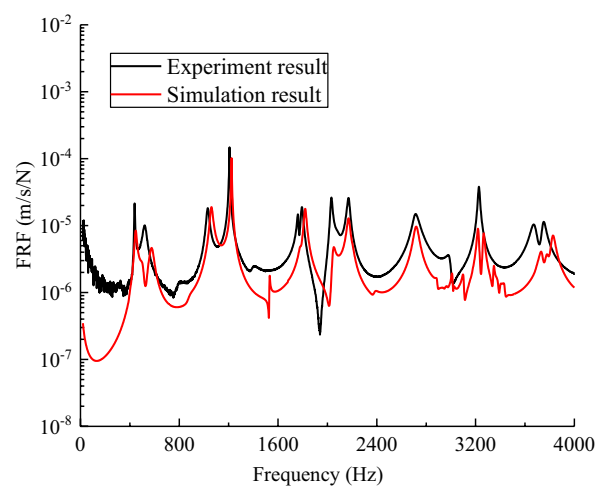

b Rim axial response

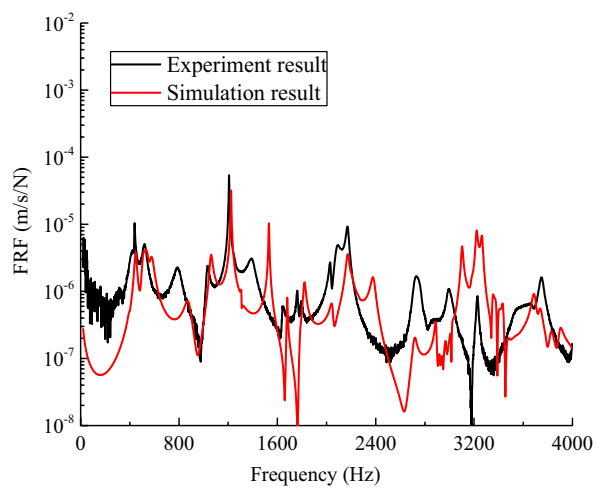

c Web 1 axial response

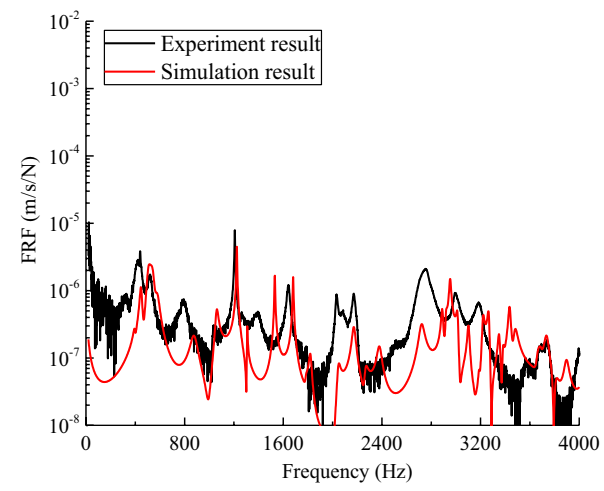

d Web 2 axial response

Figure 9 Validation of the vibration model of resilient wheel

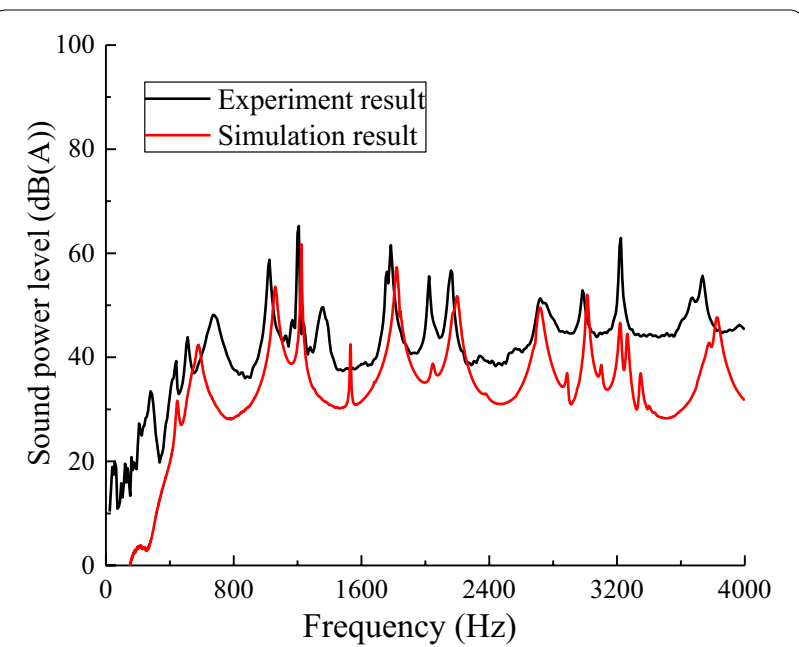

Figure 10 Validation of the sound radiation model of resilient wheel

further shows that the prediction model can be used to effectively calculate the vibration and sound radiation of a resilient wheel.

\subsection{Rail Vibration and Sound Radiation Calculation}

\subsubsection{Rail Vibration Equation}

The slab track model is established based on the infinite Timoshenko beam, as shown in Figure 11.

The rail vibration equation is shown in Eq. (3):

$$
\begin{aligned}
& \rho_{r} A_{r} \frac{\partial^{2} u_{r}}{\partial t^{2}}-\kappa_{r} A_{r} G_{r} \frac{\partial^{2} u_{r}}{\partial x^{2}}+\kappa_{r} A_{r} G_{r} \frac{\partial \Psi_{r}}{\partial x}=f(x, t) \\
& \rho_{r} I_{r} \frac{\partial^{2} \Psi_{r}}{\partial t^{2}}-E_{r} I_{r} \frac{\partial^{2} \Psi_{r}}{\partial x^{2}}-\kappa_{r} A_{r} G \frac{\partial w}{\partial x}+\kappa_{r} A_{r} G_{r} \Psi_{r}=M(x, t) .
\end{aligned}
$$

where $u_{r}$ is the vertical displacement of the rail, $\Psi_{r}$ is the rail section angle, and $x$ is the direction of the rail. $f$ and $M$ are the force and the bending moment acting on the rail, respectively. The rail material properties are expressed as Young's modulus $E_{r}$, shear modulus $G_{r}$, and density $\rho_{r}$. The parameters of the rail section are represented by the cross-sectional area $A_{r}$, moment of inertia $I_{r}$, and shear coefficient $\kappa_{r}$.

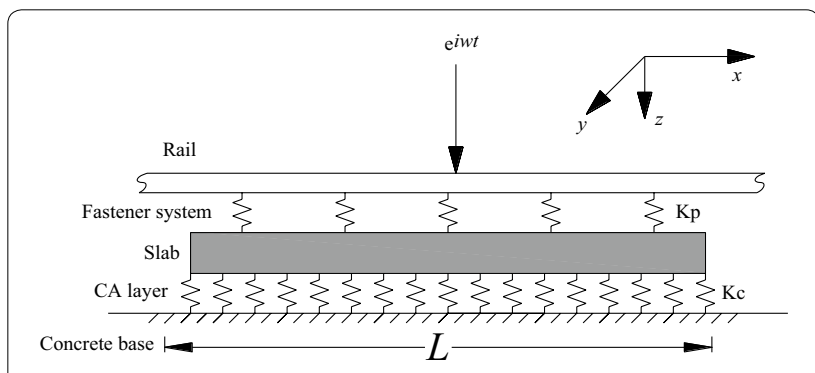

Figure 11 Sketch of the slab track and coordinate system 
The force and bending moment acting on the rail in the above formula can be written as:

$$
\begin{aligned}
& f(x, t)=f_{e}(x, t)+\sum_{j=-\infty}^{\infty} \sum_{s=1}^{S} \delta\left(x-x_{s}-j l\right) f_{j s}(t), \\
& M(x, t)=\sum_{j=-\infty}^{\infty} \sum_{s=1}^{S} \delta\left(x-x_{s}-j l\right) M_{j s}(t) .
\end{aligned}
$$

The model considers the periodic discrete support of the fasteners and slab. $\delta(\cdot)$ is the Dirac function. $f_{j s}(t)$ and $M_{j s}(t)$ represent the force and bending moment of the $s$ th fastener on the $j$ th plate acting on the rail, respectively. $x_{s}$ is the relative coordinate of the $s$ th fastener on the $j$ th slab, $l$ is the length of the slab. This model does not consider the bending moment of the wheel acting on the rail. $f_{e}(x, t)$ is the harmonic wheel/rail force and can be expressed as:

$$
f_{e}(x, t)=\delta\left(x-x_{0}\right) p_{0} e^{\mathrm{i} \omega t},
$$

where $p_{0}$ is the amplitude of the harmonic force and $x_{0}$ is the initial position coordinate of the wheel/rail force.

\subsubsection{Rail Transfer Matrix at Force Application Point}

In the frequency domain, the response of the $r$ th fastener caused by the $s$ th fastener force can be written as:

$$
\begin{aligned}
& H_{r r}(\omega)=G_{r r}(\omega)+1 / k_{p}, \quad(r=s), \\
& H_{r s}(\omega)=G_{r s}(\omega), \quad(r \neq s),
\end{aligned}
$$

where $\omega$ is the circular frequency of the simple harmonic force, $k_{p}$ is the stiffness of the fastener. $G_{r s}$ is the response of the slab under the $r$ th fastener force under the support of the continuous cement-asphalt mortar with stiffness $k_{c}$ under the $s$ th unit fastener force. This response is obtained by the modal superposition method and can be written as:

$$
G_{r s}(\omega)=\sum_{m=1}^{M} \sum_{n=1}^{N} \frac{W_{m n}\left(x_{s}, y_{s}\right)}{\left.M_{m n}\left[\omega_{m n}^{2}\left(1+\mathrm{i} \eta_{m n}\right)-\omega^{2}\right)\right]} W_{m n}\left(x_{r}, y_{r}\right),
$$

where $W_{m n}$ is the mode function of the slab, $M_{m n}$ is the modal mass of the slab, $\omega_{m n}$ is the inherent circular frequency of the slab, and $\eta_{m n}$ is the loss factor at each natural frequency. $\left(x_{s}, y_{s}\right)$ and $\left(x_{r}, y_{r}\right)$ are the coordinates of the $s$ th unit fastener force and the $r$ th fastener force, respectively. A transfer matrix $H_{r s}$ can adapt to any slab.

Because the slab is spaced apart from each other, the magnitude of the displacement response of the rail at the $r$ th fastener of the $j$ th slab can be expressed as:

$$
q_{j r}(\omega)=-\sum_{s=1}^{S} H_{r s}(\omega) \hat{F}_{j s}(\omega)
$$

Table 1 Track and material data

\begin{tabular}{ll}
\hline Parameter & Values \\
\hline Rail unit length mass $m_{r}(\mathrm{~kg})$ & 60 \\
Sleeper spacing / $(\mathrm{m})$ & 0.6 \\
Rail elastic modulus $E\left(\mathrm{~N} / \mathrm{m}^{2}\right)$ & $2.1 \times 10^{11}$ \\
Rail shear modulus $G\left(\mathrm{~N} / \mathrm{m}^{2}\right)$ & $0.77 \times 10^{11}$ \\
Rail damping loss factor $\eta_{r}$ & 0.001 \\
Rail cross-sectional area $A\left(\mathrm{~m}^{2}\right)$ & $7.69 \times 10^{-3}$ \\
Rail section moment of inertia / $\left(\mathrm{m}^{4}\right)$ & $3.217 \times 10^{-5}$ \\
Shear coefficient $K$ & 0.4 \\
Fastener stiffness $K_{p}(\mathrm{~N} / \mathrm{m})$ & $1 \times 10^{8}$ \\
Rail pad loss factor $\eta_{f}$ & 0.1 \\
\hline
\end{tabular}

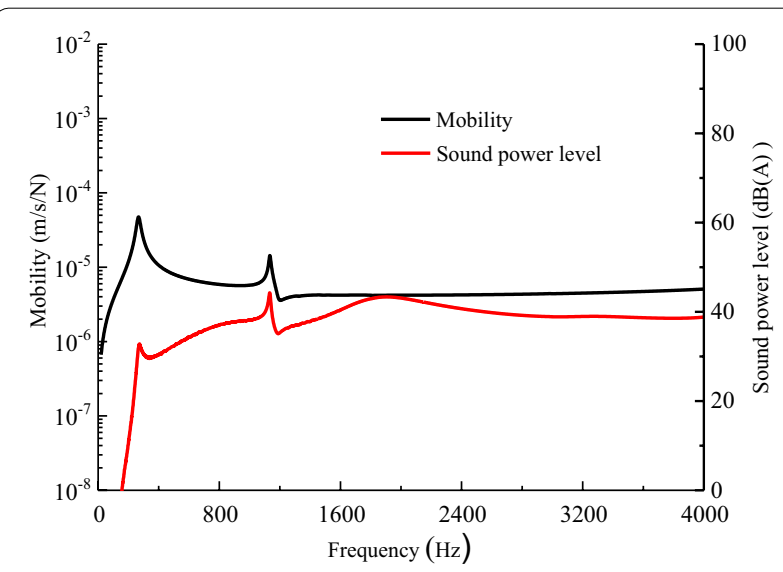

Figure 12 Rail vertical mobility and sound power level results under unit force on the rail head

$$
\begin{aligned}
& q_{j r}(\omega)=\left\{\begin{array}{c}
u_{r}(\omega) \\
\Psi_{r}(\omega)
\end{array}\right\}, \\
& \hat{F}_{j s}(\omega)=\left\{\begin{array}{c}
\hat{f}_{j s}(\omega) \\
\hat{M}_{j s}(\omega)
\end{array}\right\} .
\end{aligned}
$$

Finally, by converting Eq. (3) into the frequency domain and then substituting Eq. (8) into Eq. (3), we obtained the response $u_{r}$ of the rail in the frequency domain [29]. The parameters of the rail response calculation are listed in Table 1.

Figure 12 shows the vertical mobility and sound power level for a rail excited by a unit force. When calculating the mobility, a vertical unit force is applied at the midspan of two neighboring fasteners; the vibration response at the excitation point is obtained as the rail vertical mobility. In addition, the vibration response at other points can also be obtained, which can be used to 
calculate the sound power level of the rail by using the frequency-domain Rayleigh method.

\subsubsection{Wheel/Rail Force and Roughness}

Wheel/rail rolling noise is generated by wheel/rail force excitation. The wheel/rail force calculation method is based on the vertical interaction model of wheel-rail rolling noise [2], which is shown by Eq. (10):

$$
F=\frac{i \omega r}{Y_{r}+Y_{w}+Y_{c}},
$$

where $F$ is the vertical interaction force between wheel and rail, $Y_{r}$ is the rail mobility, $Y_{w}$ is the wheel mobility, and $Y_{c}$ is the contact mobility. The values of wheel and rail mobility are calculated and the contact mobility can be obtained according to the wheel/rail Hertz contact relationship, and $r$ is the amplitude of the wheel/rail combined roughness. Its amplitude considers the influence of the wheel/rail contact filtering. $\omega=2 \pi f$ is the circular frequency.

In the model, the measured wheel/rail roughness spectrum of a metro line is used [10], as shown in Figure 13. The roughness of wheels in this line appears as a low level. The roughness of the rail includes before-grinding state and after-grinding state, and the before-grinding state rail surface roughness is with $40 \mathrm{~mm}$ wavelength corrugation. In the calculation, the train speed is $80 \mathrm{~km} / \mathrm{h}$, and the axle load is $12 \mathrm{t}$.

\section{Prediction Results and Discussion}

\subsection{Rail Vibration and Sound Radiation Calculation}

Based on the existing resilient and standard wheel structures, the wheel/rail rolling noise excited by after-grinding rail roughness was calculated. Figure 14 shows the wheel noise and rail noise.

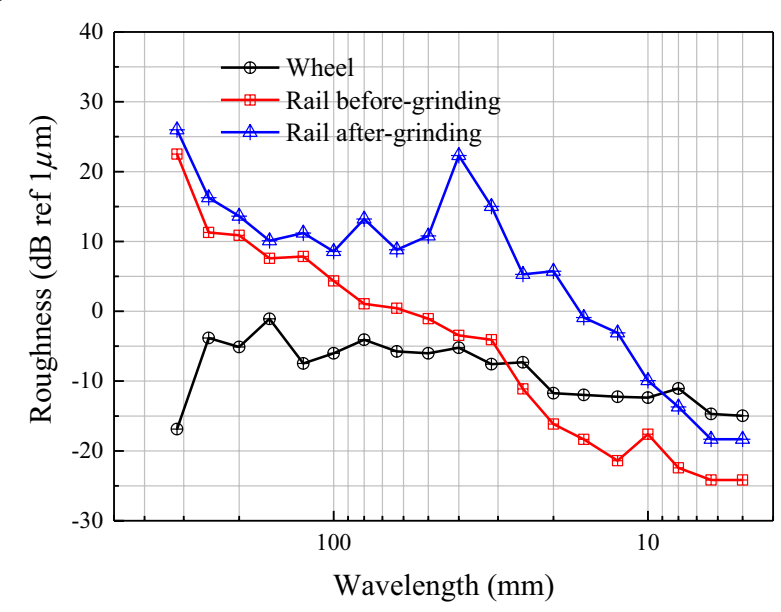

Figure 13 Measured wheel/rail roughness spectrum

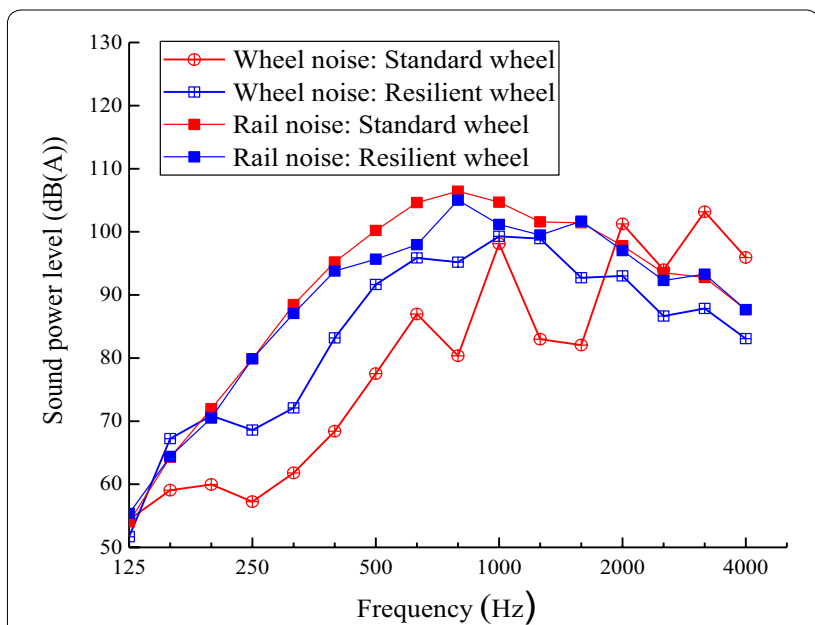

Figure 14 One-third octave band spectrum of wheel noise and rail noise under after-grinding rail roughness

It can be seen from the figure that the sound power level of the resilient wheel for frequency above $2000 \mathrm{~Hz}$ is lower than that of the standard wheel, but when the frequency is below $1600 \mathrm{~Hz}$, it is higher than that of the standard wheel. Combining the wheel vibration characteristics excited by a unit radial force (Figures $5,6,7$ ), for frequencies above $2000 \mathrm{~Hz}$, the tread radial response, rim axial response, and vibration levels of web 1 and web 2 are lower than those of the standard wheel. According to the calculation in Eq. (11) for the wheel response excited by the wheel/rail force, when the wheel has a small vibration response under the unit force, the vibration level under the wheel/rail force is also small; consequently, the sound power level of the resilient wheel is reduced.

$$
v_{w}=\frac{i \omega r Y_{w}}{Y_{r}+Y_{w}+Y_{c}} .
$$

When the frequency is below $1600 \mathrm{~Hz}$, the tread radial mobility of the resilient wheel is higher than that of the standard wheel, and the peak frequencies mainly correspond to the radial mode of the rim, which results in an increase in the rim vibration, resulting in the value of sound power level of the resilient wheel below $1600 \mathrm{~Hz}$ to be approximately $8 \mathrm{~dB}$ to $15 \mathrm{~dB}$ higher than that of the standard wheel. At $1000 \mathrm{~Hz}$, the sound power levels of the resilient wheel and the standard wheel are close because there are significant $(0,3)$ axial modal vibrations on both the resilient wheel and the standard wheel in the $1000 \mathrm{~Hz}$ band.

The noise radiated by the rail when the resilient wheel rolls over is lower than that when the standard wheel rolls over, in the range of $315 \mathrm{~Hz}$ to $1250 \mathrm{~Hz}$. This is mainly because the resilient wheel reduces the wheel/ rail force (as shown in Figure 15) in this frequency band. 


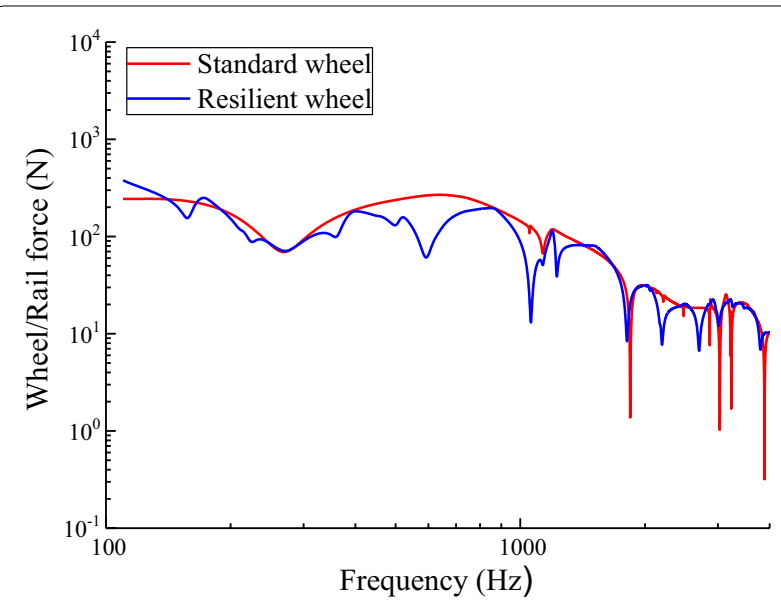

Figure 15 Frequency spectrum of wheel/rail force excited by after-grinding rail roughness

As the tread radial mobility of the resilient wheel is higher than that of the standard wheel from $315 \mathrm{~Hz}$ to $1250 \mathrm{~Hz}$, it can be observed from Eq. (9) that the wheel/ rail force is reduced, and the vibration and sound radiation of the rail under the wheel/rail force excitation is reduced. The maximum reduction occurs at $630 \mathrm{~Hz}$, which is $6.7 \mathrm{~dB}$. However, at $800 \mathrm{~Hz}$, the resilient wheel reduces the rail radiated noise by only $1.4 \mathrm{~dB}$; this is primarily because the resilient wheel generates no significant resonance peak in the $800 \mathrm{~Hz}$ band, leading to a small reduction of wheel/rail force. In addition, the effect of the resilient wheel on the sound radiation of the rail below $250 \mathrm{~Hz}$ and above $1600 \mathrm{~Hz}$ is not obvious because the resilient wheel has less influence on the wheel/rail force in these frequency bands, as shown in Figure 15.

Figure 16 shows the wheel/rail rolling noise characteristics excited by after-grinding and before-grinding rail roughness.

When the excitation is by after-grinding rail roughness, the resilient wheel reduces the wheel/rail noise in the maximum frequency bands from $315 \mathrm{~Hz}$ to $4000 \mathrm{~Hz}$; however, the noise marginally increases at $1250 \mathrm{~Hz}$ and $1600 \mathrm{~Hz}$. In the following section, the mechanism of wheel/rail rolling noise reduction by the resilient wheel is analyzed, combining the characteristics of the wheels and the radiated noise. When using the standard wheel, the wheel/rail noise in the frequency band from $315 \mathrm{~Hz}$ to $1250 \mathrm{~Hz}$ is mainly contributed by the rail. However, at $1000 \mathrm{~Hz}$, the rail noise is $15 \mathrm{~dB}$ or higher than the wheel. While using the resilient wheel, the wheel/rail noise of this frequency band is contributed by the wheel and rail, but the rail noise is still higher than the wheel noise. When compared to the standard wheel, the use of the resilient

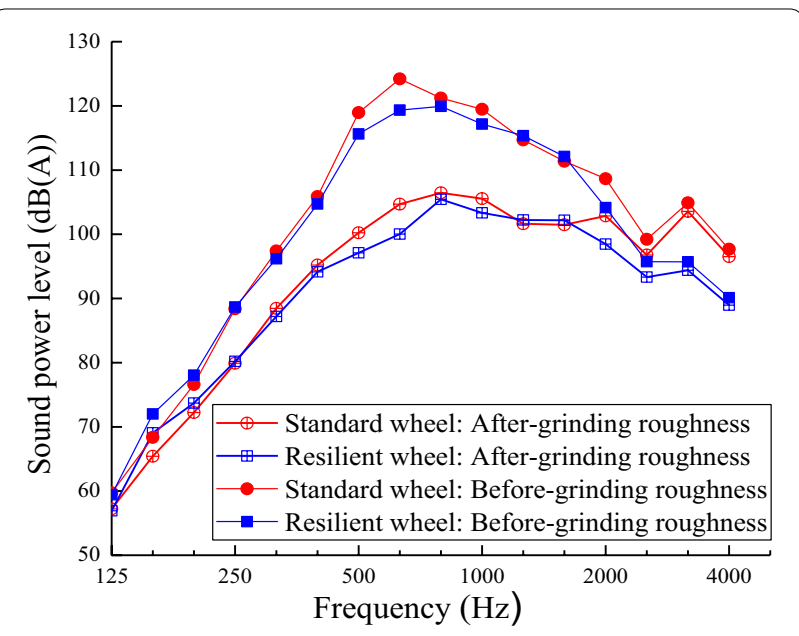

Figure 16 One-third octave band spectrum of rolling noise

wheel increases the wheel radiated noise; however, it reduces the rail radiated noise from $315 \mathrm{~Hz}$ to $1000 \mathrm{~Hz}$, and the rail radiated noise is still dominant. Therefore, the resilient wheel reduces the wheel/rail noise in the frequency band from $315 \mathrm{~Hz}$ to $1000 \mathrm{~Hz}$. At $1250 \mathrm{~Hz}$, the rail radiated noise is marginally reduced when using the resilient wheel, but the wheel radiated noise increases to a level close to the rail radiated noise, resulting in a marginal increase in wheel/rail noise. At $1600 \mathrm{~Hz}$, the rail radiated noise does not demonstrate significant change when using the resilient wheel, but the wheel radiated noise increases, resulting in a marginal increase in wheel/rail noise. Above $2000 \mathrm{~Hz}$, the rail radiated noise also does not demonstrate significant change when using the resilient wheel, but the wheel radiated noise reduces remarkably, which in turn reduces the wheel/rail noise significantly. In general, resilient wheels can effectively reduce wheel/rail rolling noise because the resilient wheel can effectively reduce rail radiating noise from $500 \mathrm{~Hz}$ to $1000 \mathrm{~Hz}$ and reduce wheel noise above $2000 \mathrm{~Hz}$. The wheel/rail noise can be reduced by $2.3 \mathrm{~dB}(\mathrm{~A})$ in the entire frequency band, and approximately $1.8 \mathrm{~dB}(\mathrm{~A})$ in the significant frequency band (from $500 \mathrm{~Hz}$ to $1250 \mathrm{~Hz}$ ) of the interior noise of metro trains [10].

Figure 16 also shows the wheel/rail rolling noise characteristics excited by before-grinding rail roughness. The contribution of the rail radiated noise to the wheel/rail rolling noise excited by the before-grinding rail roughness is absolutely dominant. Owing to the presence of short-wave corrugation, the peak frequency of wheel/ rail noise when using a standard wheel is $630 \mathrm{~Hz}$, and the noise below $400 \mathrm{~Hz}$ and above $1600 \mathrm{~Hz}$ is $10 \mathrm{~dB}$ or more lower than the peak noise of $630 \mathrm{~Hz}$. When using the resilient wheel, the wheel/rail noise can be reduced by $2.7 \mathrm{~dB}(\mathrm{~A})$ in the whole frequency band and $2.8 \mathrm{~dB}(\mathrm{~A})$ 
from $500 \mathrm{~Hz}$ to $1250 \mathrm{~Hz}$, which is higher than the reduction when excited by after-grinding rail roughness, thereby increasing the noise reduction effect of the resilient wheel on the wheel/rail noise.

\subsection{Effect of Rubber Elastic Modulus}

The rubber elastic modulus directly affects the natural frequency of the resilient wheel, which in turn affects the vibration and sound radiation characteristics. Figure 17 shows the effect of rubber elastic modulus, which equals $5 \times 10^{7} \mathrm{~Pa}, 5 \times 10^{8} \mathrm{~Pa}$, and $5 \times 10^{9} \mathrm{~Pa}$, on the wheel/rail noise excited by after-grinding rail roughness. The modal damping ratio of the wheel is simplified in calculation; its values are averaged over the frequency band according to the experimental results of the modal damping ratio. Its average in the calculation is $3 \%$ from $20 \mathrm{~Hz}$ to $1000 \mathrm{~Hz}$ and $0.5 \%$ from $1000 \mathrm{~Hz}$ to $4000 \mathrm{~Hz}$.

It can be seen from Figure 17, as the rubber elastic modulus increases, the sound power level of the wheel significantly decreases and the rail noise increases. When the rubber elastic modulus increases from $5 \times 10^{7} \mathrm{~Pa}$ to $5 \times 10^{9} \mathrm{~Pa}$, the sound power level of the wheel decreases by $9.9 \mathrm{~dB}(\mathrm{~A})$ and the rail noise increases by $2.2 \mathrm{~dB}(\mathrm{~A})$. Because the rail noise dominates the wheel/rail noise, the wheel/rail noise increases by $1.1 \mathrm{~dB}(\mathrm{~A})$.

When the rubber elastic modulus of the resilient wheel is $5 \times 10^{9} \mathrm{~Pa}$, the rail noise level when the resilient wheel rolls over is approximately the same as that of the rail noise when the standard wheel rolls over. When the rubber elastic modulus continues to increase, the wheel noise level will continue to decrease. However, the rail noise level of the resilient wheel approaches that of the standard wheel. It can be considered that when the elastic modulus of rubber reaches $5 \times 10^{9} \mathrm{~Pa}$, continuously

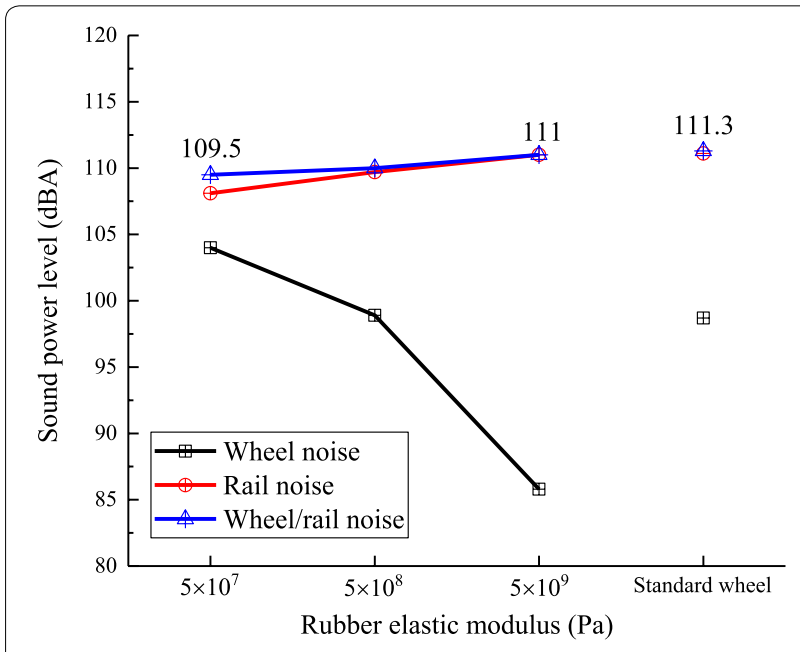

Figure 17 Effect of rubber elastic modulus on wheel/rail noise

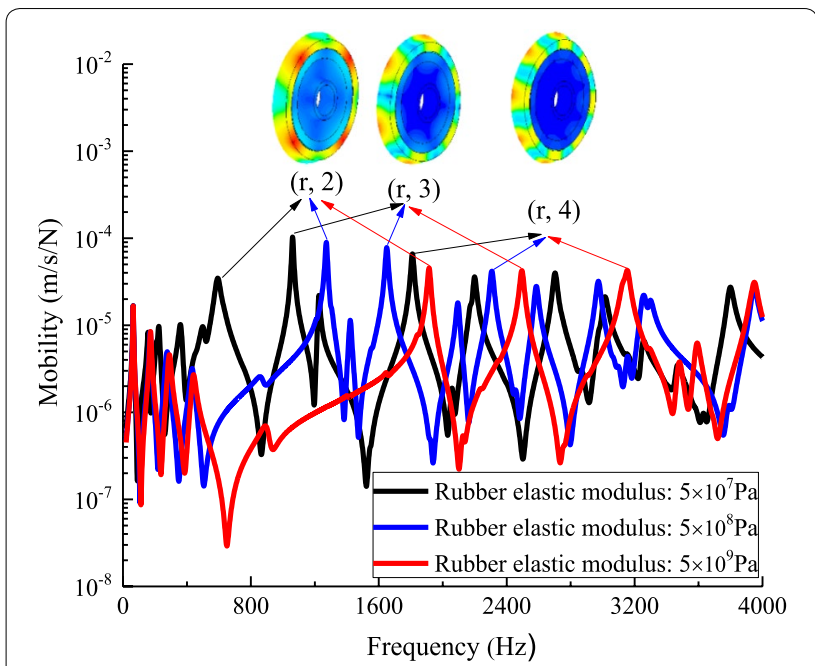

Figure 18 Effect of rubber elastic modulus on the wheel tread mobility

increasing the rubber elastic modulus will no longer affect the wheel/rail noise.

Figure 18 shows the effect of the rubber elastic modulus on the mobility of the wheel tread. It can be seen from the figure that when the rubber elastic modulus increases, the corresponding primary radial resonance frequencies of the resilient wheel move forward. This is because the metro resilient wheel mainly reduces the rail vibration only from $500 \mathrm{~Hz}$ to $1250 \mathrm{~Hz}$ to reduce the wheel/rail rolling noise. As the elastic modulus increases, the resonance frequencies of the wheel from $500 \mathrm{~Hz}$ to $1250 \mathrm{~Hz}$ decreases, and the sound radiation of the rail increases. When the rubber elastic modulus is $5 \times 10^{8} \mathrm{~Pa}$, only the mode $(\mathrm{r}, 2)$ of the wheel is approximately in the $500 \mathrm{~Hz}$ to $1250 \mathrm{~Hz}$ frequency band. When the rubber elastic modulus is $5 \times 10^{9} \mathrm{~Pa}$, there is no obvious peak in the frequency band from $500 \mathrm{~Hz}$ to $1250 \mathrm{~Hz}$.

\section{Conclusions}

(1) By performing hammer experiments on a new type of metro resilient wheel and a traditional metro standard wheel, it was observed that the radial resonance modes of the resilient wheel were relatively dense from $523 \mathrm{~Hz}$ to $1813 \mathrm{~Hz}$, when compared to the standard wheel, and the amplitude of the tread mobility was higher than that of the standard wheel. Above $1813 \mathrm{~Hz}$, the peak amplitude of the resilient wheel mobility was one to two orders of magnitude lower than that of the standard wheel, which is beneficial to reduce the noise radiated by the wheel. 
(2) Using the wheel/rail rolling noise model developed by considering the measured wheel/rail roughness excitation, we analyzed the mechanism of the wheel/rail noise reduction; it was observed that in the frequency band of the significant interior noise of metro trains (from $500 \mathrm{~Hz}$ to $1250 \mathrm{~Hz}$ ), the resilient wheel could effectively reduce the wheel/rail rolling noise because the radiated noise by the rail was reduced in the same frequency band.

(3) The elastic modulus of the rubber used in the resilient wheel demonstrated a significant influence on the vibration and noise reduction performance of the resilient wheel. When the elastic modulus increased, although the wheel radiated noise level was reduced, the rail radiated noise level increased, which in turn increased the wheel/rail system noise level. The proper elastic modulus resulted in the resilient wheels having more resonance modes between $500 \mathrm{~Hz}$ and $1250 \mathrm{~Hz}$, which significantly reduced the sound radiation of the rail.

\section{Authors' Contributions}

$X J$ conceived and designed the simulations and experiments; $X Z, J H, Y Z, S X$ and GC performed the numerical simulations and experiments; $X Z$ and BW analyzed the data; $X Z$ wrote the paper. All authors read and approved the final manuscript.

\section{Acknowledgements \\ The authors sincerely thanks to Professor X Sheng, T Zhong and R Wang of Southwest Jiaotong University for their critical discussion and reading during manuscript preparation.}

\section{Authors' Information}

Xin Zhou, born in 1988, received his PhD from Southwest Jiaotong University and is currently a lecturer at Shanghai University of Engineering Science, China. His research interests include wheel/rail noise and vibration and noise control.

Jian Han, born in 1987, is currently a postdoctoral research fellow at Southwest Jiaotong University, China.

Yue Zhao, born in 1990, is currently a lecturer at Civil Aviation Flight University of China.

Bing Wu, born in 1987, is currently a lecturer at School of Rail Transportation, Soochow University, China.

Gong Cheng, is currently a PhD candidate at State Key Laboratory of Traction Power, Southwest Jiaotong University, China.

Shenghui Xu, born in 1994, is currently a PhD candidate at State Key Laboratory of Traction Power, Southwest Jiaotong University, China.

Xuesong Jin, born in 1956, is currently a professor and a PhD candidate supervisor at State Key Laboratory of Traction Power, Southwest Jiaotong University, China. His research interests include wheel-rail interaction, rolling contact mechanics, railway vehicle system dynamics and noise of high speed train.

\section{Competing Interests}

The authors declare that they have no competing interests.

\section{Funding}

Supported by National Key R \& D Program of China (Grant No. 2017YFB1201103-08), and National Nature Science Foundation of China (Grant No. 51605318).

\section{Author Details}

1 State Key Laboratory of Traction Power, Southwest Jiaotong University, Chengdu 610031, China. ${ }^{2}$ School of Urban Rail Transportation, Shanghai University of Engineering Science, Shanghai 201620, China. ${ }^{3}$ College of Aviation Transportation Management, Civil Aviation Flight University of China, Chengdu 618307, China. ${ }^{4}$ School of Rail Transportation, Soochow University, Suzhou 215131, China.

Received: 9 April 2018 Revised: 15 May 2019 Accepted: 7 August 2019 Published online: 19 August 2019

\section{References}

[1] D J Thompson, J C Jones. A review of the modelling of wheel/rail noise generation. Journal of Sound and Vibration, 2000, 231(3): 519-536.

[2] D J Thompson. Railway noise and vibration: mechanisms, modelling and means of control. Elsevier Science \& Technology, 2008.

[3] W Liu, H Zhang, W Liu, et al. Experimental study of the treatment measures for rail corrugation on tracks with Egg fasteners in the Beijing metro. Proceedings of the Institution of Mechanical Engineers, Part F: Journal of Rail and Rapid Transit, 2018, 232(5): 1360-1374.

[4] D J Thompson, P E Gautier. Review of research into wheel/rail rolling noise reduction. Proceedings of the Institution of Mechanical Engineers, Part F: Journal of Rail and Rapid Transit, 2006, 220(4): 385-408.

[5] J F Brunel, P Dufrenoy, F Demilly, et al. Modelling of squeal noise attenuation of ring damped wheels. Applied Acoustics, 2004, 65(5): 457-471.

[6] Y M Zhang, X B Xiao, H M Shen, et al. The effect of ring dampers on noise radiation from railway wheels. Noise Control Engineering Journal, 2012, 60(3): 293-300.

[7] C J Jones, D J Thompson. Rolling noise generated by railway wheels with visco-elastic layers. Journal of Sound and Vibration, 2000, 231(3): 779-790.

[8] J Farm. Evaluation of wheel dampers on an intercity train. Journal of Sound and Vibration, 2003, 267(3): 739-747.

[9] I Merideno, J Nieto, N Gil-Negrete, et al. Theoretical prediction of the damping of a railway wheel with sandwich-type dampers. Journal of Sound and Vibration, 2014, 333(20): 4897-4911.

[10] J Han, X B Xiao, Y Wu, et al. Effect of rail corrugation on metro interior noise and its control. Applied Acoustics, 2018, 130: 63-70.

[11] D J Thompson. Wheel-rail noise generation, part II: wheel vibration. Journal of Sound and Vibration, 1993, 161(3): 421-446.

[12] T Griffin. Center truck performance on low-floor light rail vehicles. Transportation Research Board, 2006.

[13] G Kouroussis, O Verlinden, C Conti. Efficiency of resilient wheels on the alleviation of railway ground vibrations. Proceedings of the Institution of Mechanical Engineers, Part F: Journal of Rail and Rapid Transit, 2012, 226(4): 381-396.

[14] D H Koo, J C Kim, W H Yoo, et al. An experimental study of the effect of low-noise wheels in reducing noise and vibration. Transportation Research Part D: transport and Environment, 2002, 7(6): 429-439.

[15] D J Thompson, B Hemsworth, N Vincent, et al. Experimental validation of the twins prediction program for rolling noise, part 1: description of the model and method. Journal of Sound and Vibration, 1996, 193(1): 123-135.

[16] D J Thompson, P Fodiman, H Mahe, et al. Experimental validation of the twins prediction program for rolling noise, Part 2: Results. Journal of Sound and Vibration, 1996, 193(1): 137-147.

[17] P Bouvet, N Vincent, A Coblentz, et al. Optimization of resilient wheels for rolling noise control. Journal of Sound and Vibration, 2000, 231(3): 765-777.

[18] R V Haaren. Sound radiation simulation of a resilient train wheel. NS Technisch Onderzoek, 1997.

[19] B Suarez, J A Chover, P Rodriguez, et al. Effectiveness of resilient wheels in reducing noise and vibrations. Proceedings of the Institution of Mechanical Engineers, Part F: Journal of Rail and Rapid Transit, 2011, 225(6): 545-565.

[20] A Cigada, S Manzoni, M Vanali, et al. Vibro-acoustic characterization of railway wheels. Applied Acoustics, 2008, 69(6): 530-545.

[21] H Claus, W Schiehlen. Stability analysis of railways with radialelastic wheelsets. Vehicle System Dynamics, 2002, 37(sup1): 453-464.

[22] H Claus, W Schiehlen. Dynamic stability and random vibrations of rigid and elastic wheelsets. Nonlinear Dynamics, 2004, 36(2-4): 299-311. 
[23] Y Yang, J J D, L Fu, et al. Longitudinal vibration of a resilient wheel under the adhesion limit. Proceedings of the Institution of Mechanical Engineers, Part F: Journal of Rail and Rapid Transit, 2019, 233(4): 370-381.

[24] S R Singiresu. Mechanical vibrations. Addison-Wesley Publishing Company, America, 2000.

[25] M Amdi, M Souli, J Hargreaves, et al. Numerical investigation of a vibroacoustic analysis with different formulations. Computer Modeling in Engineering \& Sciences, 2012, 85(4): 329-346.

[26] D J Thompson. Wheel-rail noise generation, part I: introduction and interaction model. Journal of sound and vibration, 1993, 161(3): 387-400.

[27] A Cigada, S Manzoni, M Vanali, et al. Geometry effects on the vibro-acoustic behavior of railway resilient wheels. Journal of Vibration and Control, 2011, 17(12): 1761-1778.
[28] International Organization of Standards. ISO 3745- 2017 Acoustics Determination of sound power levels of noise sources using sound pressure - Precision methods for anechoic and hemi-anechoic rooms, Geneva: International Organization of Standards, 2017.

[29] X Sheng, T Zhong, Y Li. Vibration and sound radiation of slab high-speed railway tracks subject to a moving harmonic load. Journal of Sound \& Vibration, 2017, 395: 160-186.

\section{Submit your manuscript to a SpringerOpen ${ }^{\circ}$ journal and benefit from:}

- Convenient online submission

- Rigorous peer review

- Open access: articles freely available online

- High visibility within the field

- Retaining the copyright to your article

Submit your next manuscript at $\boldsymbol{\nabla}$ springeropen.com 